\title{
Efectes additius i de moderació en la relació dels amics antinormatius i la personalitat sobre la conducta externalitzant
}

\author{
Jordi Ortet Walker \\ al260584@uji.es \\ Francisco Javier López Fernández \\ frlopez@uji.es \\ Paula Etkin \\ etkin@uji.es \\ Sígrid Gallego Moya \\ sigridgallego@gmail.com \\ Manuel Ignacio Ibáñez Ribes \\ iribes@uji.es
}

\section{Resum}

La personalitat és una de les variables més relacionades amb les conductes externalitzants. Tanmateix, durant l'adolescència, les variables socials també són rellevants a l'hora de predir aquests tipus de conductes, especialment l'afiliació amb amics antinormatius. Els objectius d'aquest estudi van ser determinar, per una banda, en quina mesura les variables de personalitat i la conducta antinormativa dels amics influeixen en les conductes externalitzants i, per altra banda, explorar els possibles efectes interactius que aquestes variables poden mostrar en la predicció dels comportaments externalitzants.

Es va emprar una mostra de 659 adolescents de dos centres de secundària de Castelló (mitjana d'edat $=14,52$ anys, $D E=1,46 ; 52,4 \%$ xiques), que van complimentar els següents qüestionaris: Deviant Peers Scale (DPS; Gallego et al. en preparació), que mesura diverses conductes disruptives dels amics; SENA (Sánchez-Sánchez, Fernández-Pinto, Santamaría, Carrasco i del Barrio 2016), que avalua la pròpia conducta externalitzant; i el JS NEO-S (Ortet et al. 2010), que avalua les dimensions del model de cinc factors de la personalitat.

Les anàlisis de regressió lineal múltiple van mostrar que les variables de personalitat, especialment la baixa amabilitat i la baixa responsabilitat, i la conducta antinormativa dels amics predeien les conductes externalitzants. A més, es va trobar un efecte interactiu entre determinades dimensions de personalitat i la conducta dels amics en la predicció de la conducta antisocial i l'agressivitat. 
En definitiva, els efectes directes i interactius entre la personalitat i la conducta antinormativa del grup d'amics són especialment rellevants en la manifestació de comportaments externalitzants en joves. Per això, aquestes variables s'han de tenir en compte per a desenvolupar programes de prevenció i intervenció personalitzats més eficaços dirigits a la població adolescent.

Paraules clau: personalitat, externalitzant, amics, adolescents, moderació.

\section{Abstract}

Personality is one of the variables which is most related to externalizing behaviors. However, during adolescence, social variables are also relevant in predicting these types of behaviors, especially affiliation with deviant friends. The aims of this study were to determine, on the one hand, to which extent personality variables and friends' deviant behavior influence externalizing behavior and, on the other hand, exploring the possible synergistic effects between these variables in predicting externalizing behaviors.

A sample of 659 adolescents from two high schools in Castelló were used (mean age $=14.52$ years, $S D=1.46 ; 52,4 \%$ girls), that completed the following questionnaires: the Deviant Peers Scale (DPS; Gallego et al. in preparation), that measures several disruptive behaviors of friends; the SENA (Sánchez-Sánchez, Fernández-Pinto, Santamaría, Carrasco \& del Barrio 2016) that assesses externalizing behavior; and the JS NEO-S (Ortet et al. 2010), that assesses the dimensions of the Five-Factor Model of personality.

Multiple linear regression analyses showed that personality variables, especially low agreeableness and low conscientiousness, and friends' behavior predicted externalizing behaviors. Also, an interacting effect was found between certain personality dimensions and friends' deviant behavior in the prediction of antisocial behavior and aggression.

To sum up, the direct and interactive effects between personality and deviant behavior of the group of friends are especially relevant in the manifestation of externalizing psychopathological symptomatology in teens. Therefore, these variables should be taken into account for the development of more effective prevention and intervention programs aimed at the adolescent population.

Keywords: personality, externalizing, friends, adolescents, moderation.

\section{Introducció}

La personalitat és un constructe molt utilitzat en recerca per a la predicció de conductes problemàtiques, perquè es tracta d'un conjunt de predisposicions comportamentals relativament estables en el temps i consistents en distintes situacions (Digman 1990). Un estudi sobre la continuïtat dels trets de personalitat va ser l'estudi longitudinal de dues onades d'lbáñez et al. (2016). Es va administrar la versió curta del Junior Spanish NEO-PI-R (JS NEO-S; Ortet et al. 2010) als 12 i 15 anys. Els resultats van mostrar estabilitat (a més de lleugers decrements en els nivells d'amabilitat i responsabilitat) en l'estructura de la personalitat. Es van trobar alguns canvis en trets de personalitat entre els 12 i els 15 anys, però aquests canvis eren menys pronunciats que els esperables durant aquest període de desenvolupament biològic i social. Els resultats donen suport a la hipòtesi disruptiva, ja que es trobaren baixades en responsabilitat $i$, en menor mesura, amabilitat. 
El constructe de la personalitat és, per tant, una de les variables més importants en la predicció de les futures conductes antinormatives i en problemes de simptomatologia externalitzant i internalitzant. Es va dur a terme un estudi prospectiu de 5 anys (Mezquita et al. 2015) sobre la relació entre el model de cinc factors i síndromes internalitzants i externalitzants. Una mostra de 323 joves van completar el NEO-FFI en temps 1 i diverses escales de símptomes 5 anys més tard. La dimensió de neuroticisme va predir el factor internalitzant, mentre que l'extraversió, baixa amabilitat i baixa responsabilitat predeien el factor externalitzant. Una via addicional que es va trobar va ser entre la baixa amabilitat i símptomes de psicopatia.

Un altre estudi longitudinal sobre comportaments internalizants i externalitzants (Favini, Gerbino, Eisenberg, Lunetti i Thartori 2018) va emprar una mostra de 615 preadolescents italians (mitjana d'edat $=12,5$ anys). La mostra va complimentar el Big Five Questionnaire for Children als 12 anys d'edat i el Youth Self-Report a la mateixa edat i 3 anys més tard. Es van detectar quatre perfils de personalitat utilitzant l'ànàlisis de perfil latent: resilient, moderat, incontrolat i vulnerable. El perfil que es va relacionar més amb problemes internalitzants va ser el vulnerable. L'incontrolat va mostrar nivells alts de problemes externalitzants. Aquests resultats es van trobar utilitzant anàlisis de via multi-grup, controlant per gènere. Aquestes troballes corroboren la importància dels perfils de personalitat específics en la predicció de problemes adaptatius futurs en els adolescents.

Una conducta antinormativa especialment problemàtica i vigent en l'actualitat és l'assetjament o bullying. La personalitat dels adolescents ha demostrat ser un predictor d'aquest tipus de comportament d'abús contra altres. Un estudi de Walters i Espelage (2018) va trobar, en una mostra de 1161 joves participants de l'estudi Illinois Study of Bullying and Sexual Violence que la insensibilitat (callousness) i la impulsivitat (temerari, emocional) mediava la relació entre la conducta d'assetjament passada i la futura. Aquesta segona variable, la impulsivitat, mediava la continuïtat del bullying (mentre que la insensibilitat no ho feia). Aquests resultats són consistents amb la literatura disponible. El tret d'impulsivitat, lligat al neuroticisme, és una variable molt rellevant en les conductes agressives i antisocials.

Els estudis transculturals troben que les variables de personalitat habitualment associades a l'assetjament prediuen aquestes conductes en diferents contextos socioculturals. Volk, Schiralli, Xia, Zhao i Dane (2018) van realitzar un estudi comparant dades de 440 adolescents xinesos i 350 adolescents canadencs que van complimentar l'inventari de personalitat HEXACO-PR-I, junt amb un qüestionari de bullying. Regressions linials jeràrquiques van trobar que el factor d'honestedathumilitat, així com la responsabilitat, estaven relacionades de forma significativa i negativa amb la conducta d'assetjament en ambdues mostres. Per tant, existiria un perfil transcultural del bully com a impulsiu i explotador (tot i que, en la mostra xinesa, la relació amb la personalitat incloïa la baixa amabilitat i l'alta extraversió).

El grup d'amics amb el qual s'afilien els adolescents, així com la seua conducta, és un factor extremadament rellevant en les conductes externalitzants, en particular les antisocials i antinormatives, en el joves.

Les estratègies associades a la dominància, l'assertivitat positiva, són les que s'utilitzen principalment. En una mostra de 619 adolescents holandesos (mitjana d'edat $=13,1 ; 47 \%$ xiques), Vermande et al. (2018) van trobar que les estratègies assertives i coercitives eren les que predeien la dominància de manera significativa. També s'observaven efectes principals de les habilitats socials. Quant a una moderació entre estratègies i habilitats socials, aquesta només apareixia en les xiques. És a dir, la utilització de l'estratègia coercitiva s'associava a més popularitat per a les 
xiques amb nivells més alts d'habilitats de manipulació social. Aquest tipus d'estudis són molt rellevants per a entendre els mecanismes pels quals els adolescents exerceixen la seua influència sobre els seus iguals a l'hora de dur a terme conductes disruptives.

La influència dels iguals sobre les conductes problemàtiques és inclús més forta que la conducta dels pares. Un estudi de Walters (2018) va tractar de determinar dues qüestions: 1) si la delinqüència dels amics, però no la dels pares, predeia pensaments delictius proactius i 2) si l'efecte de la delinqüència dels iguals i el coneixement per part dels pares dels amics sobre els pensaments delictius proactius era additiva o interactiva. La mostra va ser de 885 (464 xiques) membres juvenils de l'Offending, Crime, and Justice Survey. L'estudi va trobar, de manera consistent amb la primera hipòtesi, que la delinqüència dels amics, però no la parental, predeia els pensaments delictius proactius, mentre que cap de les dues variables predeien pensaments delictius reactius. De manera parcialment congruent amb la segona hipòtesi, la delinqüència dels iguals i el coneixement parental, però no la seua interacció, predeien els pensaments delictius proactius. El fet de tenir amics antinormatius és un predictor molt important de la pròpia conducta antinormativa (que inclou tant les conductes agressives com les antisocials). Aquesta influència és especialment forta en l'adolescència, època en la qual l'afiliació amb els iguals explica tanta o més variància que la pròpia personalitat en la predicció de conductes problemàtiques (Vitaro, Boivin i Paolin 2018). Aquest efecte és tant significatiu que s'ha trobat que inclús una breu exposició a un igual antinormatiu prèviament desconegut incrementa la quantitat de conductes antinormatives en els adolescents (Mercer, Crocetti, Meeus i Branje 2017).

Tots els estudis citats mostren la influència important que tenen, per separat, tant la pròpia personalitat dels adolescents com el grup d'amics amb els quals s'ajunten en la predicció de conductes problemàtiques (en particular, conductes externalitzants com agressions i conducta antisocial). Tot i així, s'ha trobat que ambdues variables de forma conjunta podrien tenir un efecte sinèrgic (o multiplicador) a l'hora de predir les variables esmentades. De manera que l'afiliació amb certs amics antinormatius, junt amb una personalitat de risc podria portar a realitzar unes conductes problemàtiques molt més intenses i freqüents que quan es tenen en compte els dos predictors per separat.

Un estudi que investigava les interaccions entre la personalitat pròpia i el context ambiental a l'hora de predir conductes delictives en una mostra de 470 adolescents va mostrar que la cerca de sensacions estava parcialment mediada pels amics antinormatius. També es va trobar una interacció triple entre cerca de sensacions, amics antinormatius i control parental, de manera que les conductes antinormatives més freqüents es produïen quan es donaven tant una alta cerca de sensacions, com molts amics antinormatius i baixos nivells de control parental (Boccio i Beaver 2018).

Actualment hi ha molts estudis que analitzen aquests efectes d'interacció sobre les conductes delictives i consum de substàncies (Pocuca et al. 2018; Boccio i Beaver 2018), però pocs treballs que se centren en símptomes externalitzants concrets, com les agressions i la conducta antisocial. Així, en aquest treball es pretén dilucidar la relació entre els trets de personalitat propis, en conjunt amb la influència dels iguals, amb la conducta externalitzant en general i dos subtipus d'aquesta: els comportaments agressius i els antisocials. Aquestes dues variables dependents s'escolliren degut a les característiques de les conductes, perquè es tracta d'interaccions que tenen com a objectiu causar un perjudici a altres persones, violant normes socials o cometent agressions. Aquests tipus de comportaments concrets són els que es duen a terme en l'assetjament, per la qual cosa aquests (i no altres subtipus de comportaments externalitzants) han sigut escollits com a principal objecte d'estudi. 
Per tant, els objectius d'aquest estudi eren:

1) Examinar, per una banda, en quina mesura les variables de personalitat (segons el model dels cinc factors) i la conducta antinormativa dels amics influeixen sobre les pròpies conductes externalitzants dels adolescents.

2) Per altra banda, explorar els possibles efectes interactius que aquestes variables poden mostrar en la predicció d'aquests comportaments externalitzants, tant en general com sobre conductes externalitzants particulars com la conducta agressiva i l'antisocial.

Les hipòtesis van ser les següents:

1) Les puntuacions baixes en les variables de personalitat d'amabilitat i responsabilitat, així com una alta quantitat d'amics antinormatius, prediran les conductes externalitzants pròpies de manera significativa.

2) La interacció entre les variables de personalitat que prediguen les conductes externalitzants i els amics antinormatius tindran un efecte d'interacció sinèrgic sobre aquestes conductes externalitzants.

\section{Mètode}

\section{Participants i procediment}

La mostra emprada per aquest estudi van ser 659 adolescents de dos centres de secundària de la ciutat de Castelló, d'edats compreses entre els 11 i els 19 anys (mitjana d'edat $=14,52 ; \mathrm{DE}=1,46 ; 52,4 \%$ xiques). Es tractava dels estudiants dels cursos entre $1 \mathrm{r}$ d'ESO i $2 \mathrm{n}$ de Batxillerat, a les classes dels quals s'acudia a les hores de tutoria per a administrar una sèrie de qüestionaris. Els encarregats d'administrar el material eren estudiants del Grau de Psicologia de la Universitat Jaume I (UJI) que realitzaven el treball de fi de grau, així com els integrants del laboratori de Personalitat i Psicopatologia de l'UJI. Abans d'acudir als instituts es va acordar la participació en l'estudi amb la direcció dels centres. Vam dur regals que es van repartir entre tots els participants al final de l'estudi per a incrementar la seua motivació, així com un sorteig d'un lot de productes de I'UJI que es va entregar a un estudiant guanyador per cada classe, escollit a l'atzar. Es van repartir els qüestionaris en quatre sessions (una cada setmana). L'estudi va comptar amb el vistiplau de la Conselleria, de la Comissió Deontològica de I'UJI, dels consells escolars i amb el consentiment escrit dels pares.

\section{Mesures}

Les escales que es van administrar van ser les següents:

- Qüestionari de dades sociodemogràfiques: preguntes de resposta oberta sol-licitant informació com l'edat i el sexe (especialment rellevant per a aquest estudi) i altres qüestions com la paga setmanal percebuda o l'ocupació dels pares.

- Deviant Peer Scale (DPS; Gallego, Viruela, Camacho, Mezquita i González 2011), que mesura diverses conductes disruptives dels amics. Aquesta escala consta de 22 items, que sol-liciten informació respecte al nombre d'amics que han comés diversos tipus de conductes antinormatives en els últims 6 mesos [per exemple «(En els últims 6 mesos, quants dels teus amics...) S'han escapat de casa?»]. S'avaluen dos subtipus de conductes antinormatives: greus i lleus, a més d'una puntuació total que té en compte les conductes lleus i greus en 
conjunt. Quant a característiques psicomètriques, són adequades i es poden consultar a Gallego, Viruela, Camacho, Mezquita i González 2011.

- SENA (Sánchez-Sánchez, Fernández-Pinto, Santamaría, Carrasco i del Barrio 2016), que avalua els problemes emocionals i comportamentals més rellevants en l'adolescència, dividits entre conductes internalitzants (com ara la depressió i l'ansietat) i externalitzants (com ara les conductes agressives). Aquest estudi es va centrar en tres de les escales externalitzants: conducta externalitzant total, conducta agressiva i conducta antisocial (per exemple, "Amenace els altres per a aconseguir el que vull»). Les propietats psicomètriques són adequades $\mathrm{i}$ es poden consultar a Sánchez-Sánchez, Fernández-Pinto, Santamaría, Carrasco i del Barrio 2016.

- JS NEO-S (Ortet et al. 2010), que avalua les cinc dimensions del model de cinc factors de personalitat. Es tracta de la versió abreviada del NEO PI-R adaptada a població adolescent espanyola. Avalua les cinc dimensions i trenta facetes de personalitat d'acord amb el model dels cinc factors de Costa i McCrae (1992). El qüestionari conté 154 ítems amb resposta de tipus Likert de 5 punts, la qual conformitat o disconformitat amb l'enunciat que es presenta en un rang que oscilla entre 0 (en total desacord) i 5 (totalment d'acord). Els valors de consistència interna i estabilitat temporal son adequats. Aquestes propietats psicomètriques es poden consultar a Ortet et al. 2010.

\section{Anàlisis}

Es van dur a terme anàlisis de regressió lineal múltiple en els quals s'inclogueren tres variables dependents: la conducta externalitzant, subescala de conducta agressiva i subescala de conducta antisocial, predites en funció de les dimensions de personalitat, la quantitat d'amics amb conducta antinormativa i la interacció entre ambdues. Amb la finalitat d'obtenir una representació gràfica de les possibles interaccions, es van realitzar anàlisis de pendents simples (simple slope analysis) a partir dels paràmetres obtinguts en la regressió lineal.

Tots les anàlisis es van dur a terme mitjançant el paquet estadístic SPSS (versió 25).

\section{Resultats}

Les regressions van mostrar que els trets de personalitat $i$ els amics antinormatius, considerats de forma separada, predeien les conductes externalitzants de forma significativa (vegeu la taula 1). Concretament, per a la conducta externalitzant en general, el neuroticisme i l'extraversió es relacionaven de forma positiva i significativa $(p<0,05)$ i l'amabilitat i la responsabilitat es relacionaven de manera negativa i significativa $(p<0,05)$. Quant a la conducta agressiva, els amics antinormatius i els trets de personalitat, excepte la responsabilitat, predeien aquesta variable, en les mateixes direccions $(p<0,05)$. Per últim, respecte a la conducta antisocial, els amics antinormatius i totes les dimensions de personalitat (inclosa obertura, de forma positiva i significativa) predeien aquesta variable, en les mateixes direccions $(p<0,05)$.

La interacció entre la personalitat i els amics antinormatius va tenir un efecte sinèrgic, resultant en una quantitat molt més elevada de conductes externalitzants en general, $\mathrm{i}$ en concret de naturalesa agressiva i antisocial (vegeu la taula 1 i les figures 1, 2 i 3). Per a la conducta externalitzant, la interacció entre l'alta extraversió i els amics antinormatius era l'única significativa, que produïa un efecte multiplicador $(p<0,05)$. Quant a la conducta agressiva i l'antisocial, la primera mostrava efectes d'interacció entre els amics antinormatius i l'alta extraversió i la baixa amabilitat $(p<0,05)$. La 
segona d'aquestes conductes mostrava una interacció entre els amics antinormatius i les puntuacions baixes en amabilitat i responsabilitat $(p<0,05)$.

\begin{tabular}{|c|c|c|c|c|c|c|c|c|c|c|c|c|c|}
\hline \multirow[b]{2}{*}{ Pas } & \multicolumn{5}{|c|}{ Conducta externalitzant } & \multicolumn{4}{|c|}{ Conducta agressiva } & \multicolumn{4}{|c|}{ Conducta antisocial } \\
\hline & Variable & $\mathrm{R}^{2}$ & $\Delta \mathrm{R}^{2}$ & $\beta$ & Sig & $\mathrm{R}^{2}$ & $\Delta \mathrm{R}^{2}$ & B & Sig & $\mathrm{R}^{2}$ & $\Delta R^{2}$ & $\beta$ & Sig \\
\hline 1 & & 0,01 & 0,01 & & & 0,01 & 0,01 & & & 0,03 & 0,03 & & \\
\hline & $\begin{array}{l}\text { Edat } \\
\text { Sexe }\end{array}$ & & & $\begin{array}{l}0,06 \\
0,06\end{array}$ & $\begin{array}{l}\text { n.s. } \\
\text { n.s. }\end{array}$ & & & $\begin{array}{c}0,00 \\
-0,10\end{array}$ & $\underset{* *}{\text { n.s. }}$ & & & $\begin{array}{c}0,11 \\
-0,11\end{array}$ & $\begin{array}{l}* * \\
* *\end{array}$ \\
\hline 2 & $\begin{array}{l}\text { N } \\
E \\
O \\
A \\
C\end{array}$ & 0,40 & 0,40 & $\begin{array}{l}0,34 \\
0,25 \\
-0,01 \\
-0,33 \\
-0,25\end{array}$ & $\begin{array}{l}* * * \\
\star * * \\
\text { n.s. } \\
\star * * \\
* * *\end{array}$ & 0,27 & 0,25 & $\begin{array}{c}0,18 \\
0,14 \\
0,00 \\
-0,47 \\
-0,01\end{array}$ & $\begin{array}{l}* * * \\
* * * \\
\text { n.s. } \\
* * * \\
\text { n.s. }\end{array}$ & 0,25 & 0,23 & $\begin{array}{c}0,15 \\
0,17 \\
0,12 \\
-0,38 \\
-0,15\end{array}$ & $\begin{array}{l}* * * \\
* * * \\
* * * \\
* * * \\
* * *\end{array}$ \\
\hline 3 & DPS & 0,49 & 0,09 & 0,34 & $* * *$ & 0,40 & 0,13 & 0,40 & $* * *$ & 0,40 & 0,15 & 0,42 & $* * *$ \\
\hline 4 & $\begin{array}{l}\text { DPSxN } \\
\text { DPSxE } \\
\text { DPSxO } \\
\text { DPSxA } \\
\text { DPSxC }\end{array}$ & 0,51 & 0,02 & $\begin{array}{r}-0,04 \\
0,09 \\
0,01 \\
-0,06 \\
-0,06\end{array}$ & $\begin{array}{c}\text { n.s. } \\
* * \\
\text { n.s. } \\
\text { n.s. } \\
\text { n.s. }\end{array}$ & 0,43 & 0,03 & $\begin{array}{c}-0,03 \\
0,11 \\
-0,01 \\
-0,17 \\
-0,01\end{array}$ & $\begin{array}{c}\text { n.s. } \\
* * \\
\text { n.s. } \\
* * * \\
\text { n.s. }\end{array}$ & 0,43 & 0,03 & $\begin{array}{c}-0,06 \\
0,05 \\
0,05 \\
-0,11 \\
-0,12\end{array}$ & $\begin{array}{c}\text { n.s. } \\
\text { n.s. } \\
\text { n.s. } \\
* * \\
* * *\end{array}$ \\
\hline
\end{tabular}

Nota: ${ }^{*} p<0,05 .{ }^{* *} p<0,01 .{ }^{* *} p<0,001$. n.s.: no significatiu.

Taula 1. Conductes externalitzants $(\mathrm{DPS}=$ Deviant Peers Scale; $N=$ Neuroticisme; $\mathrm{E}=$ Extraversió; $\mathrm{O}=$ Obertura; $\mathrm{A}=$ Amabilitat; $\mathrm{C}=$ Responsabilitat)

\section{Conducta externalitzant}

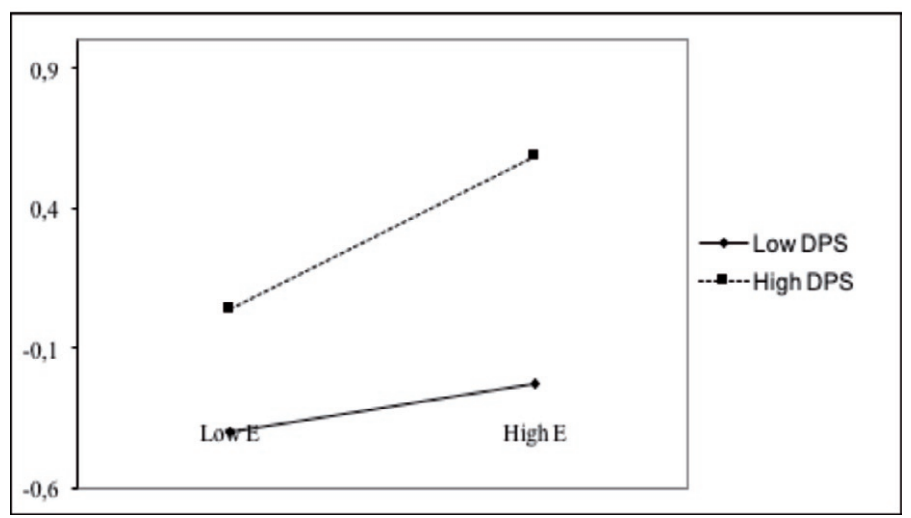

Figura 1. Conducta externalitzant $(\mathrm{DPS}=$ Deviant Peers Scale; $\mathrm{E}=$ Extraversió $)$ 
Conducta agressiva
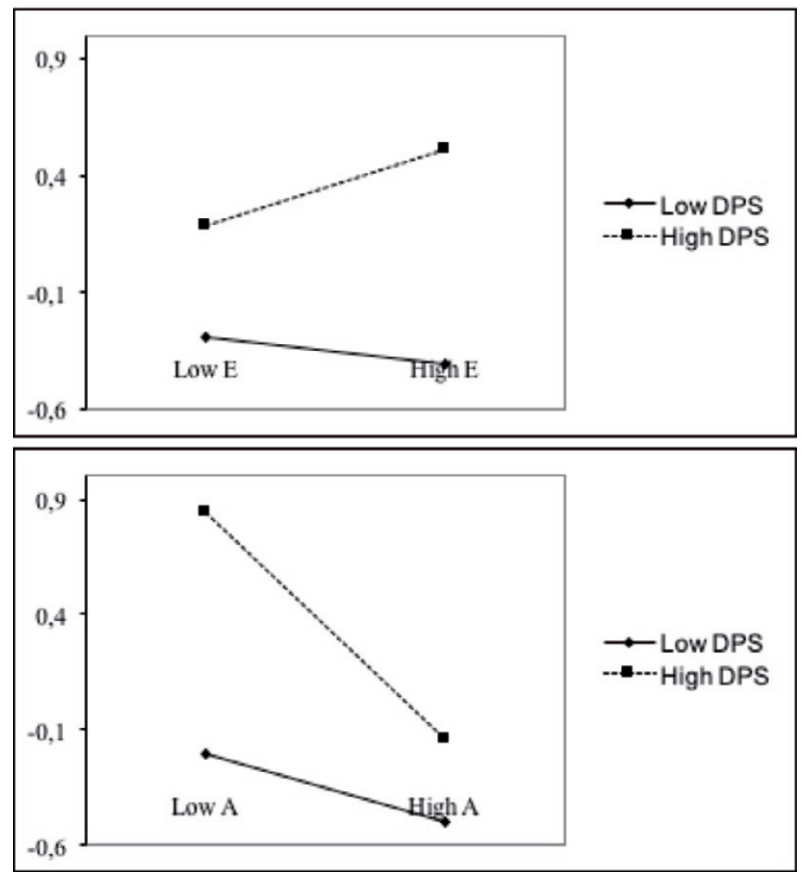

Figura 2. Conducta agressiva

\section{Conducta antisocial}
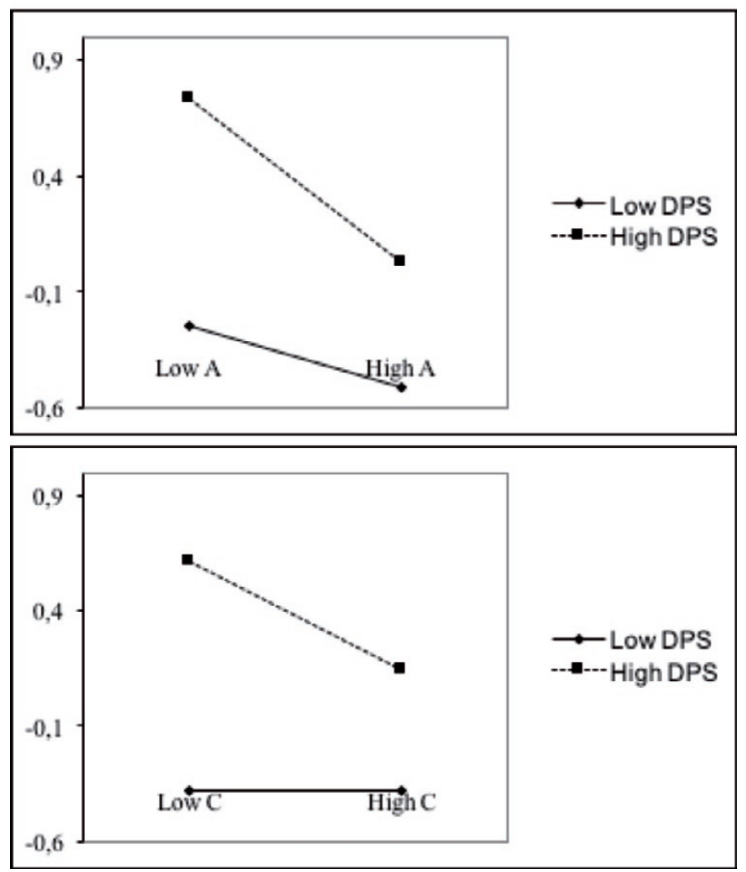

Figura 3. Conducta antisocial

(DPS = Deviant Peers Scale; $E=$ Extraversió; $A=$ Amabilitat; $C=$ Responsabilitat $)$

\section{Conclusions}

Els resultats donen lloc a les següents conclusions:

- En primer lloc, una major quantitat d'amics antinormatius, junt a puntuacions altes en extraversió, prediuen una major quantitat de conductes externalitzants de manera sinèrgica.

- En segon lloc, una major quantitat d'amics antinormatius, junt amb puntuacions altes en extraversió i baixes en amabilitat, prediuen una major quantitat de conductes agressives de manera sinèrgica.

- En tercer lloc, una major quantitat d'amics antinormatius, junt amb puntuacions baixes en amabilitat i en responsabilitat, prediuen una major quantitat de conductes antisocials de manera sinèrgica.

Respecte a les nostres hipòtesis, aquests resultats els donarien suport de manera parcial. Les puntuacions baixes en amabilitat i responsabilitat, de la mateixa manera que l'alta quantitat d'amics amb conducta antinormativa, prediuen per separat una major comissió de les conductes externalitzants estudiades (consistent amb la hipòtesi 1). No obstant, l'efecte sinèrgic significatiu dels amics antinormatius amb la baixa responsabilitat i la baixa amabilitat només es va trobar respecte a la conducta antisocial. La conducta agressiva estava moderada només per la interacció entre amics antinormatius i baixa amabilitat, mentre que el factor externalitzant en general (el conjunt d'aquests tipus de conductes) no la predeia de manera significativa cap de les interaccions. Així, només podríem confirmar la hipòtesi 2 respecte de la conducta antisocial, però no en quant a l'agressiva ni al factor externalitzant. Per últim, es van trobar efectes significatius no hipotetitzats o inconsistents amb estudis previs: l'efecte 
significatiu del tret d'extraversió sobre les conductes externalitzants, així com l'efecte sinèrgic i significatiu d'aquesta variable junt amb la quantitat d'amics antinormatius en la predicció de la conducta agressiva i el factor externalitzant. Tampoc la moderació del tret d'obertura (significativa en la predicció de la conducta antisocial) era un efecte hipotetitzat.

En consonància amb estudis previs com el de Mezquita et al. (2015), els trets d'amabilitat i responsabilitat (ambdues amb puntuacions baixes) predeien el factor externalitzant. A més, en la mateixa línia que l'estudi de Walters i Espelage (2018), la dimensió de neuroticisme (lligada amb la impulsivitat) va tenir un pes important en la predicció de les conductes externalitzants estudiades. Tot i així, els resultats del nostre estudi no reproduirien completament les troballes de Vitaro, Boivin i Poulin (2018), on s'observa que el pes de la conducta antinormativa dels amics és més alt que la dels propis trets de personalitat en la predicció de conductes disruptives. Els resultats de les nostres anàlisis estadístiques apuntarien justament el contrari, mostrant variàncies d'entre 0,09 i 0,15 per la influència dels amics, comparades amb unes d'entre 0,23 i 0,40 pels propis trets de personalitat (vegeu la taula 1 ).

Com a principal limitació de l'estudi, destacaríem que no hem disposat de mesures conductuals informades per part dels amics mateixos respecte a la seua pròpia conducta antinormativa. Seria interessant per a futurs estudis replicar aquest treball disposant d'aquesta informació per part dels propis amics dels participants. A més a més, aquest estudi és de caire transversal $i$, per tant, les interpretacions causals de la personalitat i el grup d'amics en el desenvolupament de comportaments externalitzants s'han de prendre amb cautela.

En definitiva, els efectes directes i interactius entre la personalitat (particularment les puntuacions altes en extraversió i les baixes en amabilitat i en responsabilitat) i la conducta antinormativa del grup d'amics són especialment rellevants en la manifestació de comportaments externalitzants en els joves. Per tant, aquestes variables haurien de tenir-se en compte per a desenvolupar programes de prevenció i intervenció personalitzats dirigits a la població adolescent, amb l'objectiu de pal-liar el possible desenvolupament d'aquests tipus de conductes problemàtiques. Aquests programes podrien consistir en tallers psicoeducatius i d'habilitats socials per a persones amb trets de personalitat de risc (especialment baixa amabilitat, baixa responsabilitat i alta extraversió). Els adolescents més vulnerables es beneficiarien de l'aprenentatge d'habilitats per a evitar dur a terme conductes externalitzants per pressió del grup o per les seues predisposicions temperamentals.

\section{Referències bibliogràfiques}

Boccio, Cashen M. i Kevin M. Beaver. 2018. "The influence of psychopathic personality traits, low self-control, and nonshared environmental factors on criminal involvement». Youth Violence and Juvenile Justice 16(1): 37-52.

Costa Jr., Paul T. i Robert R. McCrae. 1992. «The Five-Factor Model of Personality and Its Relevance to Personality Disorders». Journal of Personality Disorders 6(4): 343-359.

Digman, John M. 1990. «Personality structure: Emergence of the five-factor model». Annual Review of Psychology 41: 417-440.

Favini, Ainzara, María Gerbino, Nancy Eisenberg, Carolina Lunetti i Eriona Thartori. 2018. «Personality profiles and adolescents' maladjustment: A longitudinal study». Personality and Individual Differences 129: 119-125. 
Gallego, Sígrid, Ana María Viruela, Laura Camacho, Laura Mezquita i Julio Alberto González. 2011. «Adaptación española del cuestionario de las conductas antinormativas de los amigos (DPS) en adolescentes». Fòrum de recerca 16: 1039-1048.

Ibáñez, Manuel Ignacio, Ana M. Viruela, Laura Mezquita, Jorge Moya, Helena Villa, Laura Camacho i Generós Ortet. 2016. «An investigation of five types of personality trait continuity: A two-wave longitudinal study of Spanish adolescents from age 12 to age 15». Frontiers in Psychology 7: Article ID 512.

Mercer, Natalie, Elisabetta Crocetti, Wim H. J. Meeus i Susan Branje. 2017. «An experimental investigation of the influence of deviant peers on own deviancy: A replication study». Journal of Experimental Criminology 14(3): 1-10.

Mezquita, Laura, Manuel Ignacio Ibáñez, Helena Villa, Lourdes Fañanás, Jorge MoyaHigueras i Generós Ortet. 2015. «Five-factor model and internalizing and externalizing syndromes: A 5-year prospective study». Personality and Individual Differences 79: 98-103.

Ortet, Generós, Patricia Escrivá, Manuel Ignacio Ibáñez, J. Moya, Helena Villa, Laura Mezquita i María Ángeles Ruipérez. 2010. «Versión corta de la adaptación Española para adolescentes del NEO-PI-R (JS NEO-S)». International Journal of Clinical and Health Psychology 10(2): 327-344.

Pocuca, Nina, Leanne Hides, Catherine Quinn, Melanie J. White, Louise Mewton, Nicola C. Newton, Timothy Slade, Cath Chapman, Gavin Andrews, Maree Teesson, Steve Allsop i Nyanda McBride. 2018. "The interactive effects of personality profiles and perceived peer drinking on early adolescent drinking». Psychology of Addictive Behaviors 32(2): 230-236.

Sánchez-Sánchez, Fernando, Irene Fernández-Pinto, Pablo Santamaría, Miguel A. Carrasco i Victoria del Barrio. 2016. "SENA, Sistema de Evaluación de Niños y Adolescentes: proceso de desarrollo y evidencias de fiabilidad y validez». Revista de Psicología Clínica con Niños y Adolescentes 3(2): 23-34.

Vermande, Marjolijn M., Patricia A. Gilholm, Albert H. A. Reijntjes, Dave J. Hessen, Elisabeth H. M. Sterck i Anne M. Overduin-de Vries. 2018. «Is inspiring group members an effective predictor of social dominance in early adolescence? Direct and moderated effects of behavioral strategies, social skills, and gender on resource control and popularity». Journal of Youth and Adolescence 47(9): 1813-1829.

Vitaro, Frank, Michel Boivin i François Poulin. 2018. «The interface of aggression and peer relations in childhood and adolescence». En Handbook of peer interactions, relationships, and groups, ed. William M. Bukowski, Brett Laursen i Kenneth H. Rubin (284-301). New York, NY, US: Guilford Press.

Volk, Anthony A., Katerina Schiralli, Xiaoyang Xia, Junru Zhao i Andrew V. Dane. 2018. «Adolescent bullying and personality: A cross-cultural approach». Personality and Individual Differences 125: 126-132.

Walters, Glenn D. 2018. «Peers, parents, and proactive criminal thinking: Comparing additive and interactive effects in mid- to late-adolescents». Deviant Behavior 39(7): 868-877.

Walters, Glenn D. i Dorothy L. Espelage. 2018. «Cognitive insensitivity and cognitive impulsivity as mediators of bullying continuity: Extending the psychological inertia construct to bullying behavior». School Psychology Quarterly 33(4): 527536. 